Open Access

\title{
Age at smoking initiation and self-rated health among second grade high school boys and girls in Scania, Sweden, a cross- sectional study
}

\author{
Kristina Hansen*, Martin Lindström and Maria Rosvall
}

\begin{abstract}
Background: Smoking is usually initiated early in life and most adult regular smokers have started smoking before 18 years of age. A younger age at smoking initiation is associated with risk taking behaviours and worse health outcomes regarding psychological and somatic conditions, suggested to be caused by exposure during critical developmental periods. The present study aims to investigate self-rated health among second grade high school boys and girls related to age at smoking initiation ( $<14$ years of age and $\geq 14$ years of age) among current and former smokers, compared to never smokers.
\end{abstract}

Methods: Data was derived from the Scania public health survey among children and adolescents in 2012. The study was cross-sectional with retrospective information about first time cigarette smoking experiences among 3245 boys and 3434 girls in second grade of high school. Self-rated health was assessed with the question "How do you rate your general health". Associations of age at smoking initiation, current smoking status and poor self-rated health were investigated with logistic regression models.

Results: Crude odds ratios of poor self-rated health were increased for all smoking groups compared to never smokers. Former smoking boys and currently smoking girls with early smoking initiation had the highest odds ratios of poor self-rated health, with odds ratios (OR) 2.4 (95\% confidence interval (Cl): 1.5-3.7) and OR 2.9 ( $95 \%$ Cl: 2.3-3.6), respectively. After adjustments for sociodemographic factors, health-related behaviours, psychosocial factors, weight and functional disabilities, the results were attenuated, but remained statistically significant regarding former and current smoking boys with early smoking initiation, OR 2.0 (95\% Cl: 1.1-3.7) and OR 1.7 (95\% Cl: 1.1-2.4) and for current smoking girls with early and later smoking initiation, OR 2.1 (95\% Cl: 1.5-2.8) and OR 1.5 (95 \% Cl: 1.1-2.0).

Conclusion: Boys and girls in second grade of high school with early smoking initiation reported poorer self-rated health than later initiators and never smokers. Poorer self-rated health persisted also after smoking cessation among early initiating boys. Further studies are needed to understand the adverse health effects associated with timing of smoking initiation.

Keywords: Self-rated health, Smoking initiation, Smoking onset, Life-course

\footnotetext{
* Correspondence: Kristina.hansen@med.lu.se

Department of Clinical Sciences, Social Medicine and Health Policy, CRC,

Scania University Hospital, Lund University, Jan Waldenströms gata 35,

SE-205 02 Malmö, Sweden
}

\section{Biomed Central

(c) 2015 Hansen et al. Open Access This article is distributed under the terms of the Creative Commons Attribution 4.0 International License (http://creativecommons.org/licenses/by/4.0/), which permits unrestricted use, distribution, and reproduction in any medium, provided you give appropriate credit to the original author(s) and the source, provide a link to the Creative Commons license, and indicate if changes were made. The Creative Commons Public Domain Dedication waiver (http://creativecommons.org/publicdomain/zero/1.0/) applies to the data made available in this article, unless otherwise stated. 


\section{Background}

Smoking is usually initiated early in life and most adult regular smokers have started smoking before 18 years of age $[1,2]$. In several European countries, $70 \%$ or more of adult former and current smokers started smoking regularly before the age of 18 years [3]. Globally smoking prevalences among the young vary and WHO report on prevalences between 8-21\% among boys and $2-17 \%$ among girls [4]. Early smoking initiation, before 14 years of age, is more prevalent among boys and vary considerably between countries e.g., $56 \%$ in Estonia and $9 \%$ in Armenia initiate smoking before 14 years of age [5].

Smoking in Sweden has declined among men since the 1970s and among women since the 1980s [6], however, in younger age groups, 16-24 years of age, smoking has been fairly consistent over the last 10 years [7]. Among Swedish second grade high school students, $10 \%$ of the boys and $14 \%$ of the girls report daily or almost daily smoking and additionally $16 \%$ of the boys and $19 \%$ of the girls report intermittent smoking. In the same group $19 \%$ of both boys and girls report smoking before the age of 14 years [8].

Studies report more subjective physical and psychological health complaints, poorer self-rated health and lower quality of life already among adolescents associated with daily smoking, intermittent smoking and ex-smoking compared to never smokers [9-14] suggesting that smoking has a prompt connection to health.

Early adolescence is a vulnerable period in life where major physical and emotional changes are initiated including physical growth, sexual maturation, hormone changes, development of identity and mental and social development $[15,16]$. Smoking initiation during early compared to later adolescence has been associated with increased risk taking behaviours such as substance use [17], alcohol risk consumption [18], sexual risk behaviours [13] and suicidal behaviours [19]. Earlier smoking onset compared to later has further been shown to be associated with more unfavourable physical health outcomes several years after smoking initiation, even after controlling for total smoking exposure. Such an effect has been suggested to act through various pathways e.g., by modulating immune system response [20-22] causing DNA damage, diminishing organ growth [23], or initiating atherosclerotic development $[24,25]$, with more severe effects from tobacco smoke exposure during periods of growth and development [20, 23].

Furthermore, neurobiological studies suggest that early smoking has an unfavourable effect due to the ongoing brain development [2], where early smoking onset compared to later could increase the risk of long standing adverse health effects more than expected from only prolonged smoking exposure. Younger age at smoking onset, compared to later has been associated with psychological symptoms such as attention deficit hyperactivity disorder (ADHD), shorter time to onset of first anxiety disorder and earlier and more frequent episodes of major depressive disorders [17, 26-28].

Self-rated health (SRH) is a well-established measure among adults found to be a reliable outcome of physical and psychological wellbeing and a predictor of mortality [29-31]. Among adolescents self-rated health is as a measure of physical and psychological wellbeing that also include "an overall sense of function" [32, 33]. As clinical endpoints in these age groups are sparse, selfrated health might be a suitable measure of health in adolescents and young adults.

Early smoking initiation might have critical impact on future health development concerning physical, psychological and behavioural health effects, independent of smoking duration. Identifying effects related to age at smoking initiation is important when trying to understand the development of health pathways and to guide future public health efforts. To the best of our knowledge no previous study has explored the association of early and later smoking initiation, current smoking status and SRH in adolescence. In the present study we aim to investigate self-rated health among second grade high school boys and girls related to age at smoking initiation $(<14$ years of age and $\geq 14$ years of age) and current smoking status.

\section{Methods \\ Study design}

The study is cross-sectional with retrospective information about first time cigarette smoking experiences among 3245 boys and 3434 girls in second grade of high school in 2012.

\section{Study population}

This study was based on The Scania public health survey among children and adolescents conducted in 2012, addressing all 33 municipalities in the county of Scania. The study population has previously been described in detail elsewhere [34]. In short: Among pupils in the 6th and 9th grade of elementary school and second grade of high school self-reported anonymous questionnaires covering school conditions, health issues, leisure time habits, food habits, alcohol, tobacco and drug habits, were distributed and gathered in the classroom by teachers, during school hours. In all, almost $30000 \mathrm{pu}$ pils answered the survey questionnaire. Participants were informed about the survey purpose, their anonymity, their optional participation, confidentiality of answers and that the results would be used in research. Parents of the participating children and adolescents were likewise informed. Written parental consent was not required for the present study, as second grade high 
school students are considered mature enough to by themselves decide on participation in this type of public health survey in Sweden.

Inclusion criteria; the current study is a secondary study based on all 9987 of 13848 eligible pupils in second grade high school answering the questionnaire, yielding a response rate of $72 \%$. Exclusion criteria; subjects with missing data on sex $(n=139)$, conflicting, invalid or missing responses of smoking status $(n=923)$ as well as subjects that did not smoke but had tried $(n=2246)$ were excluded and reduced the study population to 3245 boys and 3434 girls and these subjects were born between 1991-1995.

\section{Definitions}

\section{Dependent variable}

Self-rated health was assessed with the question "How do you rate your general health" with optional answers being very good, good, neither good nor poor, poor and very poor. The answers were dichotomized into poor self-rated health including neither good nor poor, poor and very poor self-rated health and good self-rated health including good and very good self-rated health.

\section{Independent variables}

Smoking status was assessed with two questions; 1: "Do you smoke?" with the optional answers: "No, I have never smoked"; "No, but I have tried"; "No, I have smoked but stopped"; "Yes, every day"; "Yes, almost every day"; "Yes, when attending parties" and "Yes, sometimes" and question 2: "How old were you when (if ever) you smoked a cigarette?". Subjects reporting "No, I have smoked but stopped" were considered former smokers. Subjects were classified as current smokers if reporting daily smoking, almost daily smoking, smoking when attending parties or smoking sometimes. Former and current smokers were divided into early and later smoking initiators with a cut-off at 14 years of age. Subjects stating "No, I don't smoke but I have tried" were excluded from the analyses due to their rather low use of cigarettes.

\section{Covariates}

Parental country of birth was divided into: both parents born in Sweden, at least one parent born in Sweden and both parents born abroad. Parental employment was divided into: both parents working, one parent working and no parent working.

The variable intense alcohol consumption was constructed based on how often quantities of alcohol equivalent to $25 \mathrm{cl}$ hard liquor were consumed during the last 12 months. Examples were given in different standard containers. Subjects reporting drinking these quantities at least once a month were considered intense alcohol consumers [35]. Use of narcotic drugs was assessed with the question: "Have you used at least one narcotic drug during the last 12 months?" with optional answers, no-I have never used narcotics, no-I have not used narcotics during the last 12 months, yes-hash/marijuana, yesecstasy, yes-amphetamine, yes-other narcotics and answers were dichotomized into: No, including I have never used narcotics and no, not during the last 12 months and the remaining alternatives were dichotomized as Yes.

Not easy to talk to parents or friends if problems was assessed with the question "If you have any problems or just want to talk to someone how easy or difficult do you think it is to turn to parents or grown ups with whom you live" or "If you have any problems or just want to talk to someone how easy or difficult do you think it is to turn to friends," respectively. The optional answers were: "very easy", "rather easy", "neither easy nor difficult", "rather difficult" and "very difficult". Answers were dichotomized into easy to talk to parents or friends, respectively, including the two first alternatives and not easy to talk to parents or friends, respectively, including the three latter alternatives.

Weight categories were constructed by calculating Body Mass Index (BMI) based on self-reported weight and height with four categories; underweight; $\mathrm{BMI}<18.5$, normal weight; BMI 18.5-24.9, overweight; BMI 25-29.99 and obesity; BMI $\geq 30$ [36].

Functional disability was assessed with the question: "Do you have any of following disabilities? hearing disability, visual disability that cannot be corrected with glasses or lenses, physical disability, reading-writingdyslexia-disability, Attention Deficit Hyperactivity Disorder (ADHD) or Attention Deficit Disorder or other disability?" A dichotomous variable was constructed grouping subjects with at least one functional disability compared to none.

\section{Statistical analyses}

The study population was stratified by sex and divided into five groups; never smokers, former smokers initiating smoking before 14 years of age, current smokers initiating smoking before 14 years of age, former smokers initiating smoking at 14 years of age or older and current smokers initiating smoking at 14 years of age or older. The cut-off at 14 years of age was based on previous studies [35]. Study population characteristics related to smoking status are presented in Tables 1 and 2. Current smoking status by early or late smoking initiation is presented in Fig. 1.

Logistic regression was used to analyse the association between smoking initiation age period, current smoking status and self-rated health with the results presented in Table 3. Odds ratios of poor self-rated health and $95 \%$ 
confidence intervals were calculated and presented in a crude model and four additional models adjusted for covariates; model 1: adjusted for age, parental country of birth and parental employment, model 2: additionally adjusted for intense alcohol consumption and use of at least one narcotic drug during the last 12 months, model 3: additionally adjusted for not easy to talk to parents if problems and not easy to talk to friends if problems and model 4: additionally adjusted for weight and presence of functional disability. All statistical analyses were performed with IBM SPSS statistics version 22 .

The study was approved by the Ethical Committee at Lund University, Sweden (Dnr. no. 2013/317).

\section{Results}

In the final study population, 1467 (45\%) were never smokers, 302 (9 \%) former smokers and 1476 (45\%) current smokers among boys (Table 1). Out of the ever smoking boys $43 \%$ were early initiators and $56 \%$ were later initiators. Among girls 1613 (47 \%) were never smokers, 233 (7 \%) former smokers, and 1588 (46 \%) current smokers (Table 2). Out of the ever smoking girls $38 \%$ were early smoking initiators and $62 \%$ were later smoking initiators.

Table 1 presents characteristics of the study population by current smoking status and age at smoking initiation ( $<14$ years of age and $\geq 14$ years of age) among second

Table 1 Characteristics (\%) of high school boys by smoking status and age at smoking initiation

\begin{tabular}{|c|c|c|c|c|c|}
\hline & \multicolumn{5}{|l|}{ Boys $n=3245$} \\
\hline & \multirow{3}{*}{$\begin{array}{l}\text { Never smokers } \\
n=1467(45 \%)\end{array}$} & \multicolumn{2}{|c|}{ Early initiators $^{a}$} & \multicolumn{2}{|c|}{ Later initiators $^{b}$} \\
\hline & & Former smokers & Current smokers & Former smokers & Current smokers \\
\hline & & $n=136(4 \%)$ & $n=640(20 \%)$ & $n=166(5 \%)$ & $n=836(26 \%)$ \\
\hline \multicolumn{6}{|l|}{ Sociodemographic factors (\%) } \\
\hline \multicolumn{6}{|l|}{ Parental country of birth } \\
\hline Both parents born in Sweden & 70 & 75 & 67 & 63 & 70 \\
\hline One parent born in Sweden & 11 & 10 & 14 & 17 & 12 \\
\hline Both parents born abroad & 19 & 15 & 19 & 19 & 18 \\
\hline \multicolumn{6}{|l|}{ Parental employment } \\
\hline Both parents working & 82 & 79 & 75 & 78 & 83 \\
\hline One parent working & 15 & 17 & 17 & 19 & 15 \\
\hline No parent working & 3 & 5 & 8 & 3 & 3 \\
\hline \multicolumn{6}{|l|}{ Health related lifestyle factors (\%) } \\
\hline Intense alcohol consumption ${ }^{c}$ & 17 & 64 & 73 & 55 & 67 \\
\hline Narcotic drugs last 12 months $^{d}$ & 3 & 32 & 42 & 24 & 29 \\
\hline \multicolumn{6}{|l|}{ Psychosocial factors (\%) } \\
\hline Not easy to talk to parents if problems & 32 & 42 & 42 & 47 & 41 \\
\hline Not easy to talk to friends if problems & 28 & 26 & 24 & 20 & 22 \\
\hline \multicolumn{6}{|l|}{ Health related symptoms (\%) } \\
\hline \multicolumn{6}{|l|}{ Weight $^{\mathrm{e}}$} \\
\hline Underweight & 8 & 3 & 5 & 8 & 5 \\
\hline Normal weight & 76 & 66 & 71 & 68 & 73 \\
\hline Overweight & 14 & 24 & 18 & 15 & 17 \\
\hline Obesity & 2 & 7 & 7 & 9 & 6 \\
\hline Functional disability $^{f}$ & 21 & 39 & 39 & 41 & 28 \\
\hline Poor self-rated health & 11 & 23 & 20 & 13 & 15 \\
\hline
\end{tabular}

Characteristic (\%) of second grade high school boys by smoking status and age at smoking initiation, the Scania public health survey among children and adolescents, 2012

${ }^{a}$ Early initiators-initiating smoking $<14$ years of age

${ }^{b}$ Later initiators-initiating smoking $\geq 14$ years of age

'Intense alcohol consumption-consumtion of alcohol equivalent to $25 \mathrm{cl}$ hard liquor at least once a month during the last 12 months

${ }^{\mathrm{d}}$ Narcotic drugs-used at least one narcotic drugs during last 12 months

eWeight; underweight-Body Mass Index (BMI) <18.5, normal weight-BMI 18.5-24.9, overweight-BMI 25-29.99, obesity-BMI $\geq 30$

${ }^{f}$ Functional disability-reporting at least one disability-hearing disability, visual disability that cannot be corrected with glasses or lenses, physical disabilities,

reading-writing-dyslexia-disabilities, Attention Deficit Hyperactivity Disorder or Attention Deficit Disorder or other disability 
grade high school boys. Early initiating former smokers showed higher prevalences of having both parents born in Sweden, intense alcohol consumption, use of narcotic drugs, not easy to talk to friends if problems, overweight and poor self-rated health and lower prevalences of not easy to talk to parents if problems than later initiating former smokers. Early initiating current smokers showed higher prevalences of intense alcohol consumption, use of narcotic drugs, at least one disability and poor selfrated health and lower prevalences of both parents working than later initiating current smokers.

Table 2 presents characteristics of the study population by current smoking status and age at smoking initiation
( $<14$ years of age and $\geq 14$ years of age) among second grade high school girls. Early initiating former smokers had higher prevalences of not easy to talk to friends if problems, underweight and poor self-rated health and lower prevalence of at least one disability than later initiating former smokers. Early initiating current smokers showed higher prevalences of intense alcohol consumption, use of narcotic drugs, not easy to talk to parents if problems, not easy to talk to friends if problems, overweight, at least one disability and poor selfrated and lower prevalences of both parents born in Sweden and both parents working than later initiating current smokers.

Table 2 Characteristics (\%) of high school girls by smoking status and age a smoking initiation

\begin{tabular}{|c|c|c|c|c|c|}
\hline & \multicolumn{5}{|l|}{ Girls $n=3434$} \\
\hline & \multirow[b]{2}{*}{ Never smokers } & \multicolumn{2}{|c|}{ Early initiators ${ }^{a}$} & \multicolumn{2}{|c|}{ Later initiators ${ }^{\mathrm{b}}$} \\
\hline & & Former smokers & Current smokers & Former smokers & Current smokers \\
\hline & $n=1613(47 \%)$ & $n=89(3 \%)$ & $n=594(17 \%)$ & $n=144(4 \%)$ & $n=994(29 \%)$ \\
\hline \multicolumn{6}{|l|}{ Sociodemographic factors (\%) } \\
\hline \multicolumn{6}{|l|}{ Parental country of birth } \\
\hline Both parents born in Sweden & 70 & 70 & 67 & 70 & 71 \\
\hline One parent born in Sweden & 10 & 13 & 16 & 11 & 12 \\
\hline Both parents born abroad & 21 & 18 & 17 & 18 & 17 \\
\hline \multicolumn{6}{|l|}{ Parental employment } \\
\hline Both parents working & 81 & 83 & 74 & 80 & 81 \\
\hline One parent working & 15 & 13 & 21 & 18 & 15 \\
\hline No parent working & 4 & 4 & 5 & 2 & 4 \\
\hline \multicolumn{6}{|l|}{ Health related lifestyle factors (\%) } \\
\hline Intense alcohol consumption ${ }^{c}$ & 11 & 43 & 65 & 43 & 57 \\
\hline Narcotic drugs last 12 months $^{d}$ & 1 & 14 & 32 & 15 & 20 \\
\hline \multicolumn{6}{|l|}{ Psychosocial factors (\%) } \\
\hline Not easy to talk to parents if problems & 30 & 45 & 44 & 42 & 39 \\
\hline Not easy to talk to friends if problems & 20 & 30 & 23 & 22 & 19 \\
\hline \multicolumn{6}{|l|}{ Health related symptoms (\%) } \\
\hline \multicolumn{6}{|l|}{ Weight ${ }^{e}$} \\
\hline Underweight & 14 & 20 & 11 & 14 & 10 \\
\hline Normal weight & 75 & 63 & 73 & 73 & 79 \\
\hline Overweight & 9 & 13 & 13 & 11 & 8 \\
\hline Obesity & 2 & 5 & 3 & 3 & 3 \\
\hline Functional disability $^{f}$ & 19 & 25 & 35 & 30 & 26 \\
\hline Poor self-rated heath & 15 & 25 & 33 & 21 & 23 \\
\hline
\end{tabular}

Characteristics (\%) of second grade high school girls by smoking status and age at smoking initiation, the Scania public health survey among children and adolescents, 2012

${ }^{a}$ Early initiators-initiating smoking $<14$ years of age

${ }^{b}$ Later initiators-initiating smoking $\geq 14$ years of age

'Intense alcohol consumption-consumtion of alcohol equivalent to $25 \mathrm{cl}$ hard liquor at least once a month during the last 12 months

${ }^{\mathrm{d}}$ Narcotic drugs-used at least one narcotic drugs during last 12 months

eWeight; underweight-Body Mass Index (BMI) < 18.5, normal weight-BMI 18.5-24.9, overweight-BMI 25-29.99, obesity-BMI $\geq 30$

${ }^{f}$ Functional disability-reporting at least one disability-hearing disability, visual disability that cannot be corrected with glasses or lenses, physical disabilities, reading-writing-dyslexia-disabilities, Attention Deficit Hyperactivity Disorders or Attention Deficit Disorder or other disability 

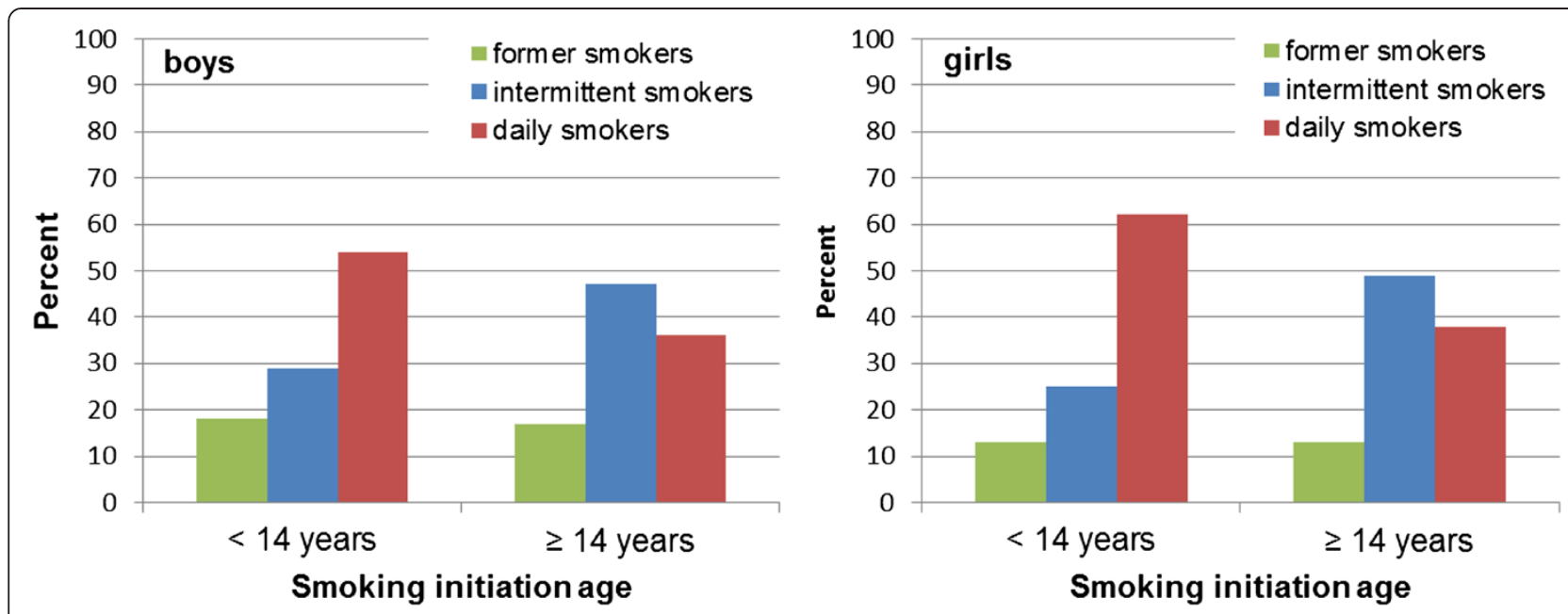

Fig. 1 Current smoking status among second grade high school students by age of smoking initiation. Distribution of current smoking status related to early or later smoking initiation among second grade high school boys and girls

Figure 1 presents the distribution of current smoking status in relation to early or later smoking initiation among boys and girls. Among those who started smoking before the age of 14 the proportion of daily smokers was higher than among those with a later smoking onset in both boys $(p<0.05)$ and girls $(p<0.05)$. The proportions of former smokers were approximately the same in both early and later smoking onset groups. In the groups with later smoking initiation, the proportions of intermittent smokers were higher than among early initiators (boys $p<0.05$, girls $p<0.05$ ).
Table 3 presents crude and adjusted odds ratios of poor self-rated health by age at smoking initiation and current smoking status among second grade high school students stratified by sex. In the crude model ORs of poor self-rated health were increased for all smoking groups compared to never smokers, most markedly for former and current smokers with early smoking initiation among both boys and girls. After adjustments for age, parental country of birth, parental employment, intense alcohol consumption, use of at least one narcotic drug during the last 12 months, not

Table 3 Odds ratios and $95 \% \mathrm{Cl}$ of poor self-rated health of early and later smoking initiators

\begin{tabular}{|c|c|c|c|c|c|c|c|c|c|c|}
\hline & \multicolumn{10}{|c|}{ Poor self-rated health } \\
\hline & Crude & $\mathrm{Cl}$ & Model $1^{a}$ & $\mathrm{Cl}$ & Model $2^{b}$ & $\mathrm{Cl}$ & Model $3^{c}$ & $\mathrm{Cl}$ & Model $4^{d}$ & $\mathrm{Cl}$ \\
\hline \multicolumn{11}{|l|}{ Boys } \\
\hline Never smokers & 1 & & 1 & & 1 & & 1 & & 1 & \\
\hline Early initiators former smokers & 2.4 & $1.5-3.7$ & 2.1 & $1.3-3.4$ & 2.2 & $1.3-3.6$ & 1.9 & $1.1-3.3$ & 2.0 & $1.1-3.7$ \\
\hline Early initiators current smokers & 2.0 & $1.6-2.6$ & 1.9 & $1.4-2.5$ & 1.8 & $1.3-2.5$ & 1.7 & $1.2-2.4$ & 1.7 & $1.1-2.4$ \\
\hline Later initiators former smokers & 1.3 & $0.8-2.0$ & 1.1 & $0.7-1.9$ & 1.0 & $0.6-1.8$ & 0.9 & $0.5-1.7$ & 0.9 & $0.5-1.6$ \\
\hline Later initiators current smokers & 1.5 & $1.1-1.9$ & 1.5 & $1.1-1.9$ & 1.4 & $1.1-2.0$ & 1.3 & $0.9-1.8$ & 1.4 & $1.0-2.0$ \\
\hline \multicolumn{11}{|l|}{ Girls } \\
\hline Never smokers & 1 & & 1 & & 1 & & 1 & & 1 & \\
\hline Early initiators former smokers & 2.0 & $1.2-3.3$ & 1.7 & $1.0-3.0$ & 1.7 & $1.0-3.1$ & 1.5 & $0.8-2.8$ & 1.5 & $0.8-2.9$ \\
\hline Early initiators current smokers & 2.9 & $2.3-3.6$ & 2.6 & $2.1-3.3$ & 2.4 & $1.8-3.1$ & 2.1 & $1.6-2.9$ & 2.1 & $1.5-2.8$ \\
\hline Later initiators former smokers & 1.6 & $1.03-2.4$ & 1.5 & $1.0-2.4$ & 1.5 & $1.0-2.4$ & 1.3 & $0.8-2.2$ & 1.3 & $0.7-2.1$ \\
\hline Late initiators current smokers & 1.8 & $1.4-2.2$ & 1.7 & $1.4-2.1$ & 1.6 & $1.3-2.1$ & 1.5 & $1.2-1.9$ & 1.5 & $1.1-2.0$ \\
\hline
\end{tabular}

Crude and adjusted odds ratios (OR) and $95 \%$ confidence interval (Cl) of poor self-rated health by early ( $<14$ years) or late ( $\geq 14 y e a r s)$ smoking initiation and current smoking status among second grade high school students, stratified by sex. The Scania public health survey among children and adolescents, 2012

${ }^{a}$ Model 1-adjusted for age, parental country of birth and parental employment

${ }^{\mathrm{b}}$ Model 2-adjusted for model 1 and intense alcohol consumption and use of narcotic drugs last 12 months

${ }^{c}$ Model 3-adjusted for model 2 and not easy to talk to parents and not easy to friends if problems

${ }^{\mathrm{d}}$ Model 4-adjusted for model 3 and weight and functional disability 
easy to talk to parents if problems, not easy to talk to friends if problems, weight and functional disability in the final model, the increased OR of poor self-rated health were attenuated, but remained statistically significant for former and current smoking boys with early smoking initiation, OR $=2.0$ (95\% CI: 1.1-3.7) and OR $=1.7$ (95\% CI: 1.1-2.4) and current smoking girls with early and later smoking initiation, OR $=2.1$ (95\% CI: $1.5-2.8)$ and $\mathrm{OR}=1.5$ (95\% CI: 1.1-2.0).

\section{Discussion}

Boys and girls in the second grade of high school with early smoking initiation (before 14 years of age) generally reported poorer self-rated health than later initiators and never smokers. Poorer self-rated health persisted also after smoking cessation among early initiating boys.

Adolescence is a growth period that marks the transition from childhood to adulthood, and can be divided into early $10-13$ years, middle $14-16$ years and late $17-19$ years adolescence based on stages of development [15]. During early adolescence major physical and emotional changes are initiated including physical growth, sexual maturation, hormone changes, development of identity, mental and social development $[15,16]$. These changes will continue to progress during mid adolescence and are completed in late adolescence [15]. Development periods are considered vulnerable to external exposure as cell proliferation and differentiation are accelerated and mutagenic alterations can appear [37]. Theories suggest that earlier smoking initiation during a vulnerable development period could have more severe health effects than later smoking initiation $[2,23]$. Neurobiological studies report that early smoking initiation might affect brain development by modulating glutaminergic, dopaminergic and serotonergic systems and further affect emotional life, intellectual capacity and reactions to drugs [2,38]. Previous studies have also shown associations between early initiation of smoking and poor psychological health such as depression, anxiety, and ADHD [17, 26-28]. However, results are inconclusive concerning the temporal directions. A younger compared to older initiation age has further been associated with chronic disease independently of the extent of prior tobacco exposure with regard to cardiovascular disease [24], peripheral vascular diseases [25], squamous cell carcinoma of the cervix [20] and lung cancer [21, 22].

In the present study, early compared to later initiating currently smoking boys and girls less often had both parents working. A previous review study supports these findings and report on earlier smoking initiation in lower socioeconomic groups [39]. In a national survey from the US early smoking initiation was associated with low socioeconomic status based on education, employment and income [18].
The present study showed higher prevalences of intense alcohol consumption, use of narcotics and daily smoking among early smoking initiators compared to later initiators. Such higher smoking intensity might theoretically have more serious effects on the developing adolescent body compared to less intense smoking. A younger age at smoking initiation has also in previous studies been linked to risk taking behaviors such as alcohol use [18], drug use, [17] suicidal [19], sexual risk behaviors [13] and transition to daily smoking [40].

The results of the present study imply that poor health in late adolescence is connected to early smoking initiation. Such poor self-rated health persisted even after smoking cessation among early initiating boys. This might indicate that smoking initiation in young ages is connected with a persistent effect on health even after cessation. Furthermore, possibly those with the strongest effects on health due to smoking quit to a higher degree than those experiencing less health effects.

Early inequalities in health need to be addressed promptly and at the relevant time span to maximize individual and public health benefits. Prevention efforts directed towards young adolescents should emphasise short-term effects, but also consider the possible longterm effects of smoking exposure during extra vulnerable periods in life. Comprehending long-term effects of smoking such as cancer and chronic obstructive pulmonary disease is possibly difficult in younger ages. Using self-rated health, effects on health associated with smoking that emerge already among adolescents are made visible. Public health strategies aimed to hinder smoking initiation are the most important, but also efforts aimed at supporting smoking cessation need to start at an early age.

\section{Strengths and limitations}

Self-rated health is considered a reliable and valid measure among early-and middle adolescents and young adults [33] and is an internationally used measure associated with morbidity and mortality [30, 31]. Furthermore, the data material allows for adjustments for potential confounders, however, it is not possible to fully exclude residual confounding. Socioeconomic status is associated with SRH health in adolescence and adulthood [12, 32, 41, 42] and could possibly influence our investigated associations. We have adjusted for socioeconomic status as parental employment, but it is possible that this variable might not fully account for the effect of socioeconomic status. Almost all adolescents in Sweden attend high school [43], making it possible to reach a high proportion of adolescents through class-room surveys. The proportion of students smoking before 14 years of age in the study group was approximately the same as in national studies and around $19 \%[8]$. 
A limitation in the present study is the cross-sectional design with retrospective information about age at smoking initiation. The lack of information on self-rated health at the time of smoking initiation makes it hard to ascertain the temporal direction in the association between smoking onset and SRH later in adolescence. Furthermore, it is difficult to distinguish effects of age at smoking onset from effects of smoking duration and thus a cumulative health effect from smoking. Moreover, risks of recall bias and reporting bias are problems connected to self-reported measures. However, the fact that the questionnaire was anonymous and no connections to individuals could be made enhances the possibilities of truthful reporting. Furthermore, second grade high school students are considered mature enough to by themselves decide on participation in this type of public health survey in Sweden. Validation of self-reported smoking has in previous studies shown satisfactory agreement concerning report of never, current and former smoking status $[44,45]$. In the main analyses we chose to exclude subjects that did not smoke but had tried smoking due to its theoretically smaller health effects. However, in an additional analysis combining never smokers and those who tried smoking, we found similar patterns of increased adjusted odds ratios (AOR) of poor self-rated health among early initiating former smoking boys, $\mathrm{AOR}=2.0$ (95 \% CI:1.1-3.6), early initiating currently smoking boys, AOR $=1.6$ (95 \% CI:1.22.3), early initiating former smoking girls $\mathrm{AOR}=1.4$ (95 \% CI:0.7-2.7) and early initiating currently smoking girls $\mathrm{AOR}=1.9$ (95\% CI:1.5-2.6) as in the main analysis. Complete information on smoking status was missing on 923 students who were excluded from the analyses. Students with such missing information showed no consistent association with unfavourable life style factors compared to the group with complete data on smoking in that they less often reported intense alcohol consumption, but more often reported overweight or obesity. Furthermore, there were no differences in SRH between the two groups.

Post hoc sample size calculations generally showed good enough power to detect differences in SRH between investigated smoking groups and never smokers in both boys and girls, however, with low power in the group later initiators former smokers. Given a larger sample size in this group might result in statistically significant differences in SRH also in boys.

\section{Conclusion}

Boys and girls in the second grade of high school with early smoking initiation generally reported poorer selfrated health than later initiators and never smokers. Such poor self-rated health persisted also after smoking cessation among early initiating boys. Further studies are needed to understand the adverse health effects associated with the timing of smoking initiation.

\section{Abbreviations}

ADHD: Attention deficit hyperactivity disorder; AOR: Adjusted odds ratios; BMI: Body mass index; Cl: Confidence interval; OR: Odds ratio; SRH: Self-rated health.

\section{Competing interests}

The authors declare that they have no competing interest.

\section{Authors' contributions}

$\mathrm{KH}$ has contributed to the conception of this work, the analysis of the data, the interpretation and the discussion of the results, the drafting, writing and revision of the contents. MR has contributed to the conception of this work, the interpretation and the discussion of the results, and revision of the contents. ML has contributed to the discussion of the results, and the revision of the contents. All authors have read and approved the final manuscript.

\section{Acknowledgements}

This study was supported by, Swedish Research Council Linnaeus Centre for Economic Demography (VR 79), Swedish ALF Government Grant Dnr M 2011/1490, Swedish ALF Government Grant Dnr M 2011/1816, and the Research Funds of the University Hospital in southern Sweden (SUS). We thank the Region Scania for providing data from the 2012 Scania public health survey of children and adolescents.

Received: 21 April 2015 Accepted: 26 October 2015

Published online: 18 November 2015

\section{References}

1. Chassin L, Presson CC, Sherman SJ, Edwards DA. The natural history of cigarette smoking: predicting young-adult smoking outcomes from adolescent smoking patterns. Health Psychol. 1990;9:701-16.

2. Lydon DM, Wilson SJ, Child A, Geier CF. Adolescent brain maturation and smoking: What we know and where we're headed. Neurosci Biobehav Rev. 2014;45:323-42.

3. Filippidis FT, Agaku IT, Vardavas Cl. The association between peer, parental influence and tobacco product features and earlier age of onset of regular smoking among adults in 27 European countries. Eur J Public Health. 2015:25:814-8.

4. World Health Organization. Tobacco Free Initiative (TFI) Global youth survey (GYTS). 2008. http://www.cdc.gov/tobacco/global/gtss/tobacco_atlas/pdfs/ tobacco_atlas.pdf. Accessed 15 July 2015.

5. Currie C, Zanotti C, Morgan A, Currie D, de Looze M, Roberts C, et al., editors. Social determinants of health and well-being among young people. Health Behaviour in School-aged Children (HBSC) study: international report from the 2009/2010 survey. Copenhagen: WHO Regional Office for Europe; 2012. Health Policy for Children and Adolescents, No. 6.

6. Guttormsson U, editor. Drogutveckling i Sverige 2011. CAN rapport No 130 [Drug trends in Sweden 2011] Centralförbundet för alkohol-och narkotikaupplysning (CAN). Stockholm: The Swedish Council for Information on Alcohol and Other Drugs (CAN)]; 2012. In Swedish.

7. Statistics Sweden. [Statistiska central byrån (SCB)]. ULF-undersökningar av levnadsförhållanden 2012. [Living Conditions Surveys 2012] http://www.scb.se/ulf/. Accessed 20 Jan 2015. (In Swedish).

8. Leifman H, editor. Drogutveckling i Sverige 2012. CAN rapport No 133. [Drug trends in Sweden 2012] Centralförbundet för alkohol-och narkotikaupplysning (CAN). Stockholm: TThe Swedish Council for Information on Alcohol and Other Drugs (CAN)]; 2013. In Swedish.

9. Dube SR, Thompson W, Homa DM, Zack MM. Smoking and health related quality of life among US adolescents. Nicotine Tob Res. 2013;15:492-500.

10. Wang MP, Ho SY, Lo WS, Lai MK, Lam TH. Smoking is associated with poor self-rated health among adolescents in Hong Kong. Nicotine Tob Res. 2012;14:682-7.

11. Holmen TL, Barrett-Connor E, Holmen J, Bjermer L. Health problems in teenage daily smokers versus nonsmokers, Norway, 1995-1997: the Nord-Trøndelag Health Study. Am J Epidemiol. 2000;151:148-55.

12. Tremblay $S$, Dahinten $S$, Kohen D. Factors related to adolescents' self-perceived health. Health Rep. 2003;14(Suppl):7-16. 
13. Hansen BT, Kjaer-Krüger S, Munk C, Tryggvadottir L, Sparén P, Hagerup-Jenssen M, et al. Early smoking initiation, sexual behavior and reproductive health - a large population-based study of Nordic women. Prev Med. 2010;51:68-72.

14. Botello-Harbaum M, Haynie DL, Murray KW, lannotti RJ. Cigarette smoking status and recurrent subjective health complaints among US school-aged adolescents. Child Care Health Dev. 2011;37:551-8.

15. U.S Department of Health and Human Services. Get Organized: A Guide to Preventing Teen Pregnancy The National Campaign to Prevent Teen pregnancy. (September 1999). http://aspe.hhs.gov/sites/default/files/pdf/ 122381/pch2_0.pdf. Accessed 25 March 2015.

16. World Health Organization. Maternal, newborn, child and adolescent health. Adolescent development. 2015. http://www.who.int/maternal_child_adolescent/ topics/adolescence/dev/en. Accessed 25 March 2015.

17. Hanna EZ, Grant BF. Parallels to early onset alcohol use in the relationship of early onset smoking with drug use and DSM-IV drug and depressive disorders: findings from the National Longitudinal Epidemiologic Survey. Alcohol Clin Exp Res. 1999;23:513-22.

18. Grant BF. Age at smoking onset and its association with alcohol consumption and DSM-IV alcohol abuse and dependence: results from the National Longitudinal Alcohol Epidemiologic Survey. J Subst Abuse. 1998;10:59-73.

19. Dong-Sik K, Hyun-Sun K. Early Initiation of Alcohol Drinking, Cigarette Smoking, and Sexual Intercourse Linked to Suicidal Ideation and Attempts: Findings from the 2006 Korean Youth Risk Behavior Survey. Yonsei Med J. 2010;51:18-26.

20. Appleby P, Beral V. Berrington de González A, Colin D, Franceschi S, Goodill A, et al. Carcinoma of the cervix and tobacco smoking: collaborative reanalysis of individual data on 13,541 women with carcinoma of the cervix and 23,017 women without carcinoma of the cervix from 23 epidemiological studies. International Collaboration of Epidemiological Studies of Cervical Cancer. Int J Cancer. 2006;118:1481-95.

21. Hegmann KT, Fraser AM, Keaney RP, Moser SE, Nilasena DS, Sedlars M, et al. The effect of age at smoking initiation on lung cancer risk. Epidemiology. 1993:4:444-8.

22. Kapeu AS, Luostarinen T, Jellum E, Dillner J, Hakama M, Koskela P, et al. Is smoking an independent risk factor for invasive cervical cancer? A nested case-control study within Nordic biobanks. Am J Epidemiol. 2009;169:480-8.

23. Wiencke JK, Kelsey KT. Teen smoking, field cancerization, and a "critical period" hypothesis for lung cancer susceptibility. Environ Health Perspect. 2002;110:555-8.

24. Huxley RR, Yatsuya H, Lutsey PL, Woodward M, Alonso A, Folsom AR. Impact of Age at Smoking Initiation, Dosage, and Time Since Quitting on Cardiovascular Disease in African Americans and Whites The Atherosclerosis Risk in Communities Study. Am J Epidemiol. 2012;175:816-26.

25. Planas A, Clará A, Marrugat J, Pou JM, Gasol A, de Moner A, et al. Age at onset of smoking is an independent risk factor in peripheral artery disease development. J Vasc Surg. 2002;35:506-9.

26. Upadhyaya HP, Deas D, Brady KT, Kruesi M. Cigarette smoking and psychiatric comorbidity in children and adolescents. J Am Acad Child Adolesc Psychiatry. 2002;41:1294-305.

27. Milberger S, Biederman J, Faraone SV, Chen L, Jones J. ADHD is associated with early initiation of cigarette smoking in children and adolescents. Am Acad Child Adolesc Psychiatry. 1997;36:37-44.

28. Jamal M, Van der Does AJ, Penninx BW, Cuijpers P. Age at smoking onset and the onset of depression and anxiety disorders. Nicotine Tob Res. 2011;13:809-19.

29. Singh-Manoux A, Martikainen P, Ferrie J, Zins M, Marmot M, Goldberg M. What does self-rated health measure? Results from the British Whitehall II and French Gazel cohort studies. J Epidemiol Community Health. 2006;60:364-72.

30. Idler EL, Yael B. Self-rated health and mortality: a review of twenty-seven community studies. J Health Soc Behav. 1997;38:21-37.

31. Burström B, Fredlun P. Self-rated health: Is it as good a predictor of subsequent mortality among adults in lower as well as in higher social classes? J Epidemiol Community Health. 2001;55:836-40.

32. Vingilis ER, Wade TJ, Seeley JS. Predictors of adolescent self-rated health. Analysis of the National Population Health Survey. Can J Public Health. 2002:93:193-7.

33. Fosse NE, Haas SA. Validity and Stability of Self-reported Health Among Adolescents in a Longitudinal. Nationally Representative Survey Pediatrics. 2009;123:496-501.
34. Lindström M, Modén B, Rosvall M. Country of birth, parental background and self-rated health among adolescents: a population-based study. Scand J Public Health. 2014;42:743-50.

35. Gripe I, editor. Skolelevers drogvanor 2013. CAN rapport 139. [Alcohol and Drug Use among Students 2013] Centralförbundet för alkohol-och narkotikaupplysning (CAN). Stockholm: The Swedish Council for Information on Alcohol and Other Drugs (CAN).]; 2013. In Swedish.

36. World Health Organization. Global Database on Body Mass Index. BMI classification. 2006. http://apps.who.int/bmi/index.jsp?introPage= intro_3.html. Accessed 15 March 2015.

37. Birnbaum LS, Fenton SE. Cancer and developmental exposure to endocrine disruptors. Environ Health Perspect. 2003;111:389-94.

38. Bertrand D. The possible contribution of neuronal nicotinic acetylcholine receptors in depression. Dialogues Clin Neurosci. 2005;7:207-16.

39. Schaap MM, Kunst AE. Monitoring of socio-economic inequalities in smoking: learning from the experiences of recent scientific studies. Public Health. 2009:123:103-9.

40. Vega WA, Gil AG. Revisiting drug progression: long-range effects of early tobacco use. Addiction. 2005;100:1358-69.

41. Kunst AE, Bos V, Lahelma E, Bartley M, Lissau I, Regidor E, et al. Trends in socioeconomic inequalities in self-assessed health in 10 European countries. Int J Epidemiol. 2005;34:295-305.

42. Ahnquist J. Sociala determinanter för hälsa-en fråga om social eller ekonomiskt kapital. [Social structures and socioeconomic patterns are the major determinants of population health]. Socialmedicinsk tidskrift. 2012;89(4-5):347-65 (In Swedish).

43. Statistics Sweden. [Statistiska central byrån (SCB)]. Statistikdatabasen. 2015. http://www.statistikdatabasen.scb.se/pxweb/sv/ssd/?rxid=1972a61e-8ff246eb-af8d-1231d5dd804c. Accessed 10 August 2015.

44. Patrick DL, Cheadle A, Thompson DC, Diehr P, Koepsell T, Kinne S. The validity of self-reported smoking: a review and meta-analysis. Am J Public Health. 1994;84:1086-93.

45. Wong SL, Shields M, Leatherdale S, Malaison E, Hammond D. Assessment of validity of self-reported smoking status. Health Rep. 2012;23:47-53.

\section{Submit your next manuscript to BioMed Central and take full advantage of:}

- Convenient online submission

- Thorough peer review

- No space constraints or color figure charges

- Immediate publication on acceptance

- Inclusion in PubMed, CAS, Scopus and Google Scholar

- Research which is freely available for redistribution

Submit your manuscript at www.biomedcentral.com/submit

C Biomed Central 